\title{
Case study - design and implementation of a high density cemented hydraulic fill system at OZ Mineral's Prominent Hill mine
}

\author{
Matthew Helinski \\ Outotec Pty Ltd \\ James Shaw \\ Oz Minerals Ltd
}

\begin{abstract}
SUMMARY: The combination of recent advancements in paste fill technology and some unfortunate incidents with poorly managed hydraulic fill systems has seen the implementation of Cemented Hydraulic Fill systems in Australian mines reduce significantly in recent years. This paper describes a high density cemented hydraulic fill system that has performed very well in recent years at OZ Mineral's, Prominent Hill Operations, Malu underground Mine. The paper details the design methodology and specific features of the system that were developed to address the underground mining demands. This is followed by a description of how the fill system was implemented and the innovative management systems used on an ongoing basis to maximise production while managing safety risks. Based on data gathered during this period the success and failure of various design considerations are discussed.
\end{abstract}

Keywords: High Density Hydraulic Fill, Design Principles, Operational Experience

\section{INTRODUCTION}

OZ Minerals owns and operates the Prominent Hill underground copper gold mine in South Australia. Underground mining at Prominent Hill commenced in 2010 with the development of the Ankata Mine, and then subsequently the Malu underground mine. The Ankata mine voids are filled with pastefill, while Cemented Hydraulic Fill (CHF) is adopted to meet initial backfilling requirements in the Malu underground mine. This paper describes the design and operational experience for the Malu CHF system.

Stoping operations in the Malu underground mine commenced in 2014. 2019 annual mine physicals included 12.5 kilometres of mine development, and production of $3.3-3.5$ million tonnes of ore hauled from the underground mine using trucks. In the Malu mine sublevels have been at 25 and $50 \mathrm{~m}$ intervals with $75 \mathrm{~m}$ high open stopes with a nominal footprint dimensions of $20 \mathrm{~m}$ by $20 \mathrm{~m}$.

Due to the ongoing resource definition work at this time, a backfill solution was sought, that satisfied the mining requirements with relatively low capital investment. A study was initiated to address this and, giving consideration to the proposed mining geometries and schedule, CHF was considered a feasible solution.

This paper presents the results of detailed design, analysis and testwork carried out to develop a very high density cemented hydraulic fill system for the Malu mine. In addition, this paper also presents the system implementation as well as the challenges and triumphs incurred throughout operation of this system. 
This paper illustrates that, with the correct approach to design and operation, CHF can provide a cost-effective solution to satisfying the needs of many underground bulk mining operations.

\section{SYSTEM DESIGN}

CHF systems are typically very simple, consisting of cyclone desliming/dewatering of mine tailings, binder addition (to the underflow product) and turbulent flows through the underground reticulation system to the stope.

In addition to a simple lower capex solution, for filling the Malu underground mine it was also the intention that the proposed hydraulic fill plant would later be relocated to the Ankata Mine to facilitate filling of secondary stopes with uncemented high density hydraulic fill. To address this requirement, Outotec originally proposed a compact "skid mounted" cemented hydraulic fill plant, similar to Outotec's HF-Compact product, presented in Figure 1.

\subsection{Process design testwork and analysis}

While the hydraulic fill manufacturing process is very simple, as noted by Liston (2011), subtle errors in the system design can create a legacy of negative issues during operation. To ensure this wasn't the case an extensive laboratory scale testwork program was undertaken.

It is well documented (Cowling et at. 1988, Kuganathan, 2002) that the key to safe CHF operations is careful pore water management. This is typically achieved through campaigns of "filling" and "resting", where the stope is allowed to drain pore water (without addition of
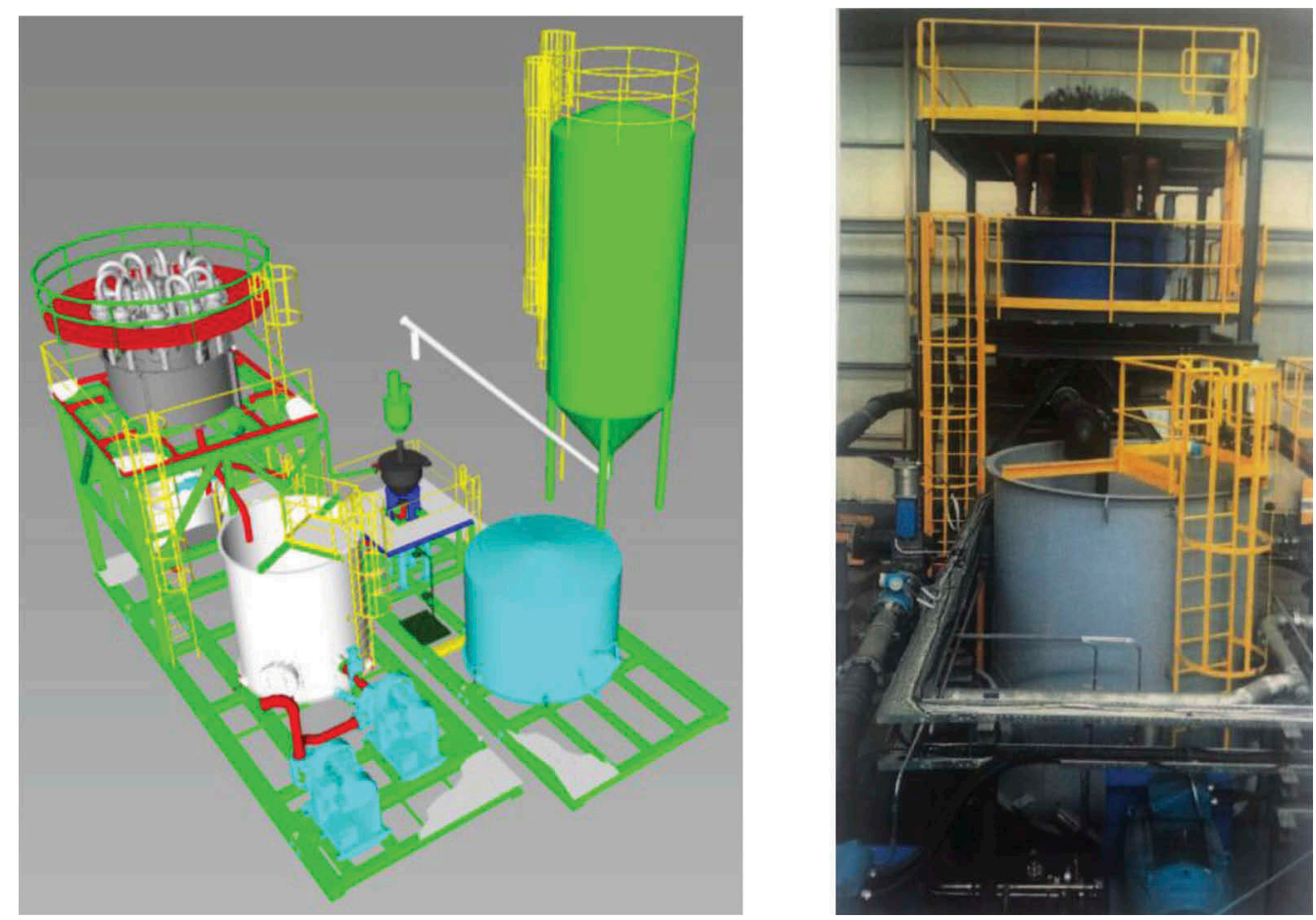

Figure 1. Schematic and photograph showing the originally proposed skid mounted fill plant model. 
more fill water) during the "the resting periods". The duration of filling periods relative to resting periods directly impacts the ability to fill a given stope (and in-turn the mining cycle). The quantity of water to be drained is controlled by the placed fill density, while the rate that free water drains is controlled by the fill permeability. As these characteristics are controlled by the cyclone underflow characteristics, and the cyclone underflow characteristics are controlled by the cyclone configuration, critical to success of a hydraulic fill system is careful design and operation of the cyclone desliming circuit.

Design of the desliming circuit was initially completed using cyclone simulations and laboratory scale "gravity decanting" to remove fines. Results from this testwork are presented in Figure 2, which shows the decanted PSD and permeability for the resulting material.

The results presented in Figure 2 show the samples created from "decanting" to be "well graded". The nature of this grading curve means relatively low recoveries, but high fines content, which leads to the low permeability presented in Figure 2. Interestingly, even though the "1 min x 5 pours" grading curve has significantly less fines than the industry accepted maximum fines criteria (less than $10 \%$ finer than $10 \mu \mathrm{m}$ ), due to adverse mineralogy, the resulting permeability is very low, at $20 \mathrm{~mm} / \mathrm{hr}$.

To assess the implications of this relatively low permeability on the filling/resting schedule a typical Malu stope was modelled using the Outotec Water Balance Model (Helinski \& Grice, 2007). Output from this model is presented in Figure 3. This figure shows the fill surface, water table surface (saturated zone) and stope-drawpoint intersection pore water pressure plotted against time throughout filling. The "zig-zag" steps in the model represent discrete periods of filling and resting, where the fill schedule was set to maintain the water surface (blue line) below the fill surface (black line) throughout filling.

The results presented in Figure 3 show that, with a fill permeability of $20 \mathrm{~mm} / \mathrm{hr}$ (maximum measured for the decanted samples) it would be expected to require 60 days to fill a typical stope. This was too long for the proposed mining schedule.

Given the unfavourable "bench scale" underflow properties it was decided to complete full scale cyclone simulations. The cyclone test rig is fitted with a complete cyclone and is configured to allow the cyclone setup, operating pressures and feed properties to be adjusted to allow the underflow product to be optimised. A photograph showing the test apparatus is presented in Figure 4. Also presented in Figure 4 is a comparison between the PSD curve of the sample created using the decanting method and that from the cyclone trial.

Figure 4 shows that, relative to the decanting method, separation through full scale cyclone classification provides a far more uniformly graded cyclone underflow. Optimisation testing showed that dilution of the cyclone feed resulted in increased uniformity, resulting in an
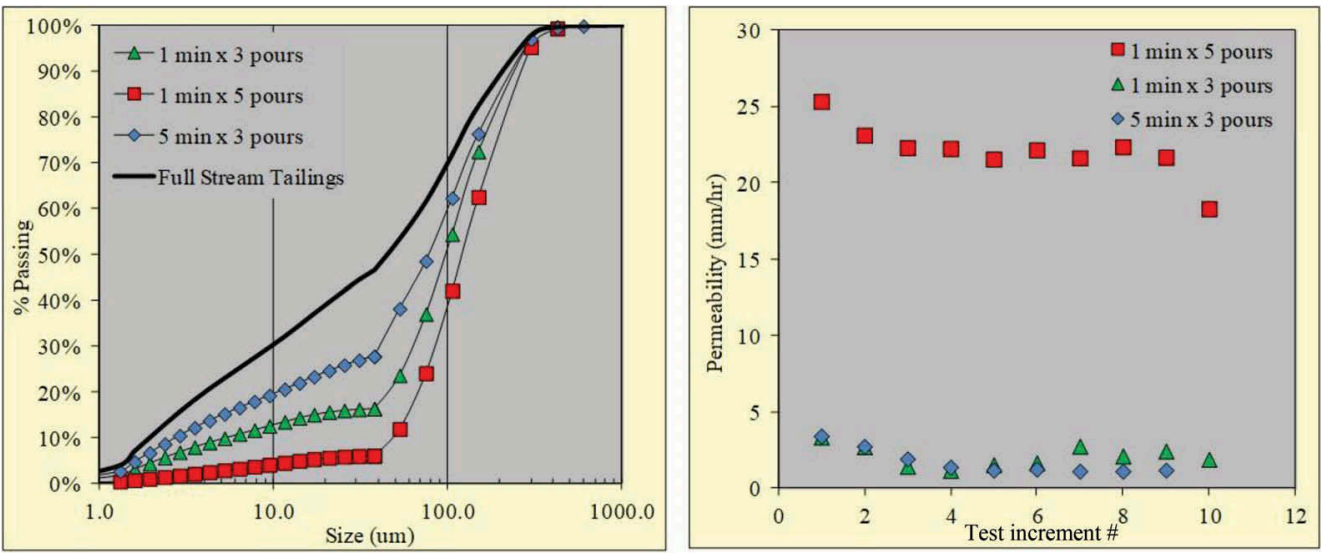

Figure 2. PSD and permeability of samples made using the laboratory decant method. 


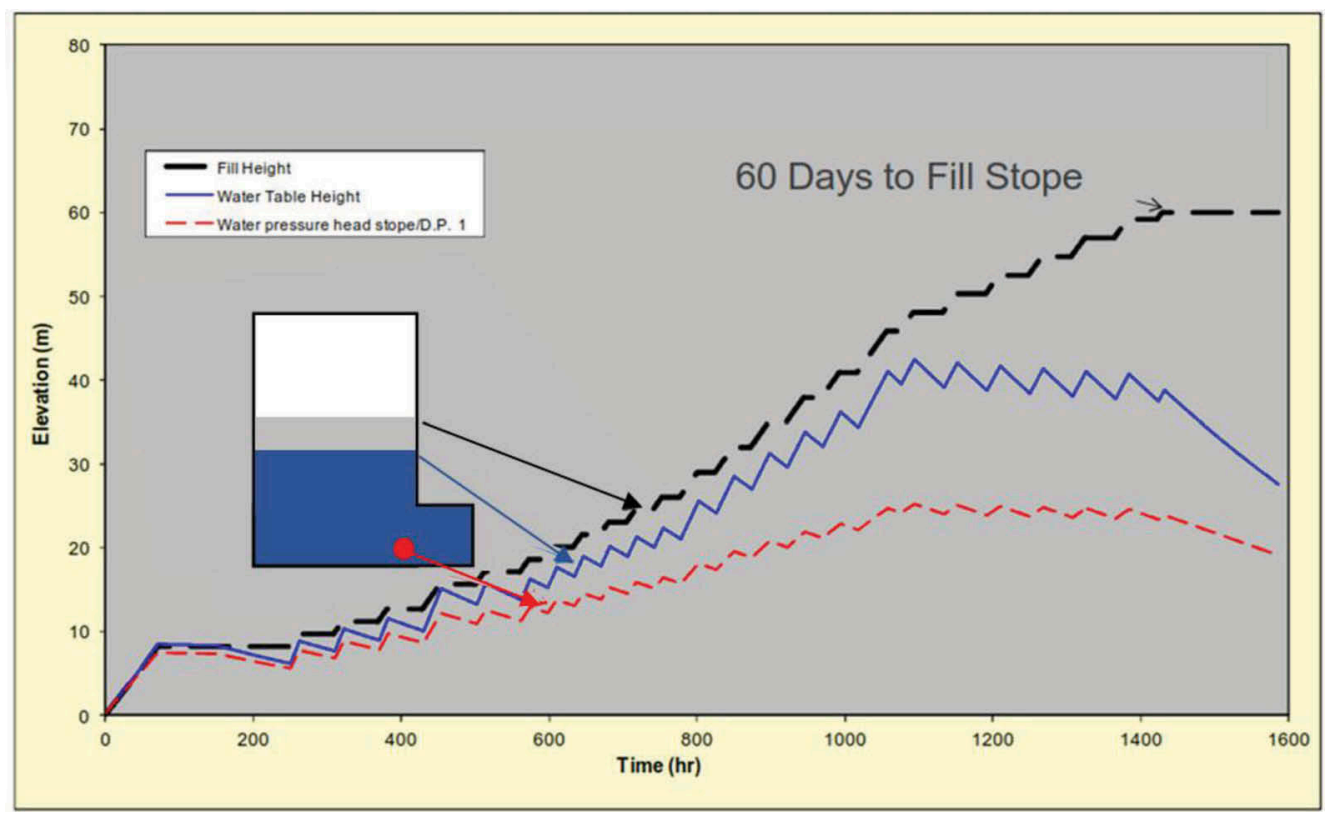

Figure 3. Water balance model for typical Malu stope with $17 \mathrm{~mm} / \mathrm{hr}$ permeability.
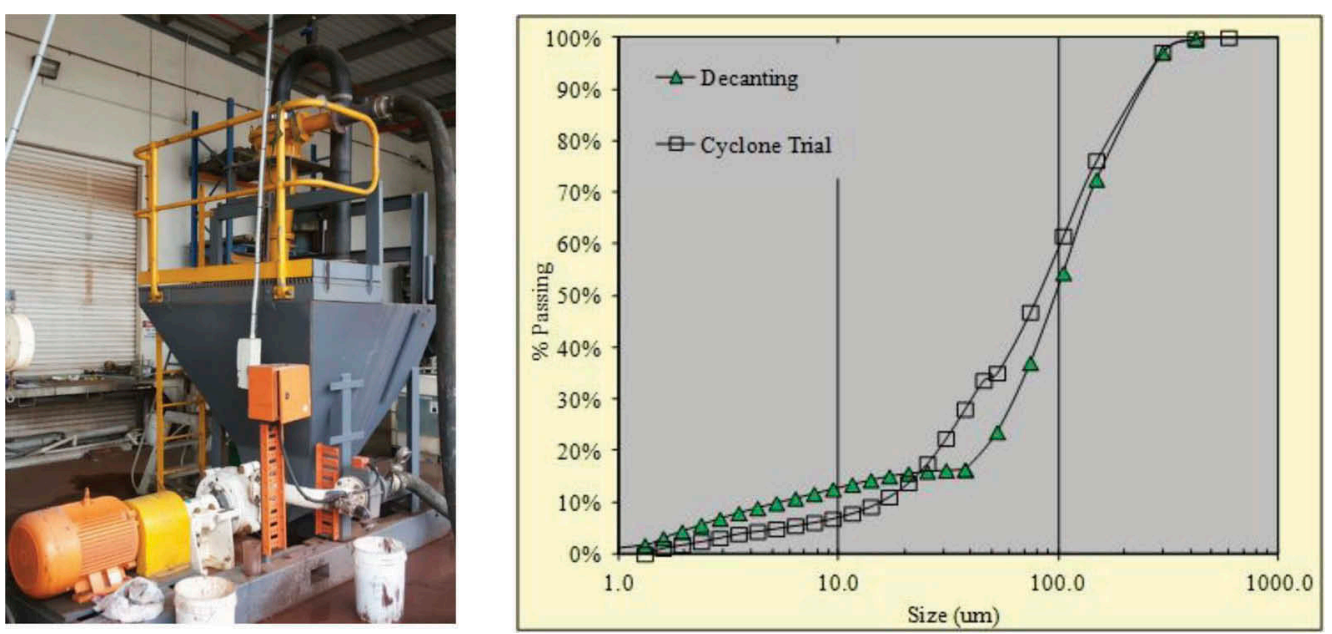

Figure 4. Cyclone test rig and cyclone trial results.

underflow product with increased permeability and solids content. Figure 5 presents the cyclone underflow permeability plotted against the cyclone feed solids concentration.

The impact of the improved underflow product on the underground mining operation is illustrated in Figure 6, which presents the water balance model output for the design underflow product. Figure 6 shows the permissible filling sequence with a fill permeability of $32 \mathrm{~mm} / \mathrm{hr}$ and placed solids concentration of $77 \%$, illustrating that a typical stope could be safely filled within 30 days. 


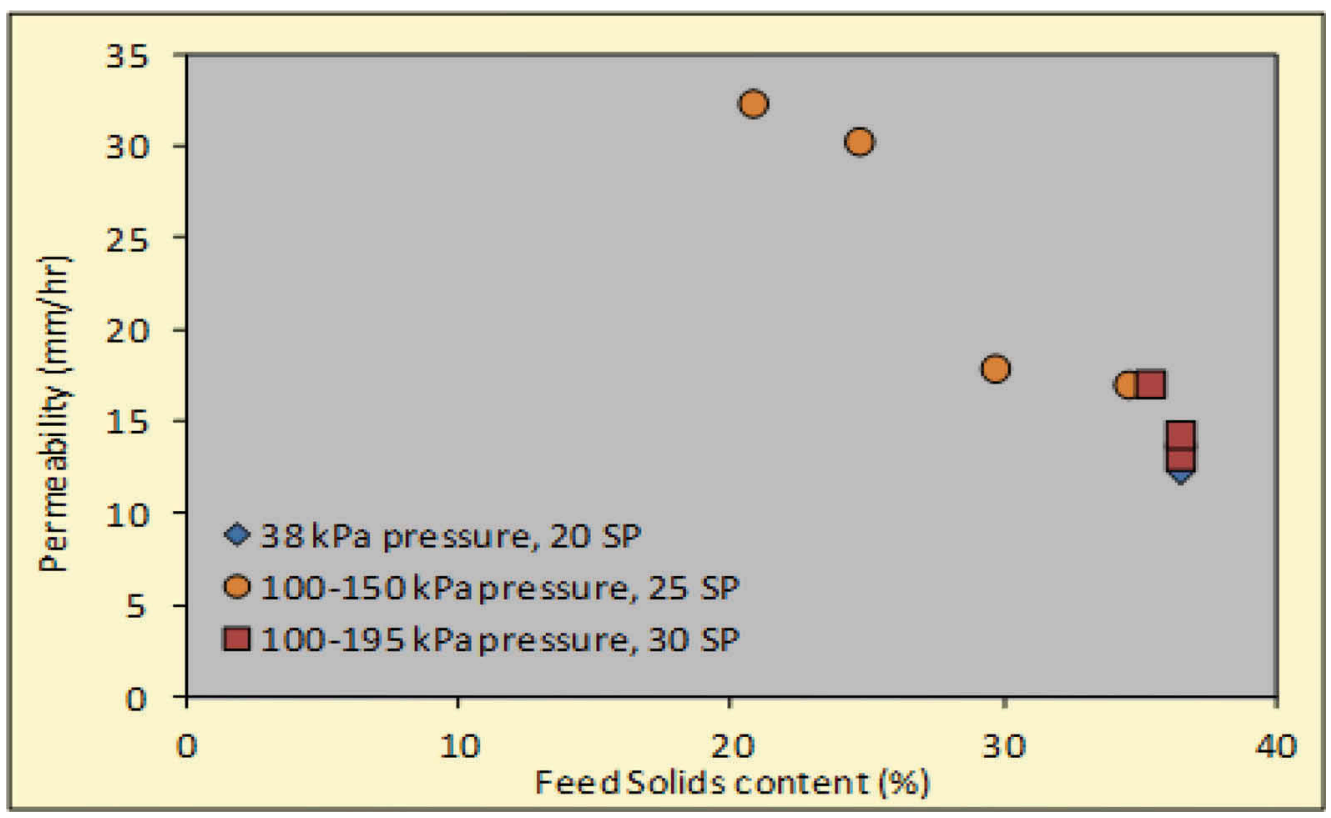

Figure 5. Cyclone feed density versus cyclone underflow permeability.

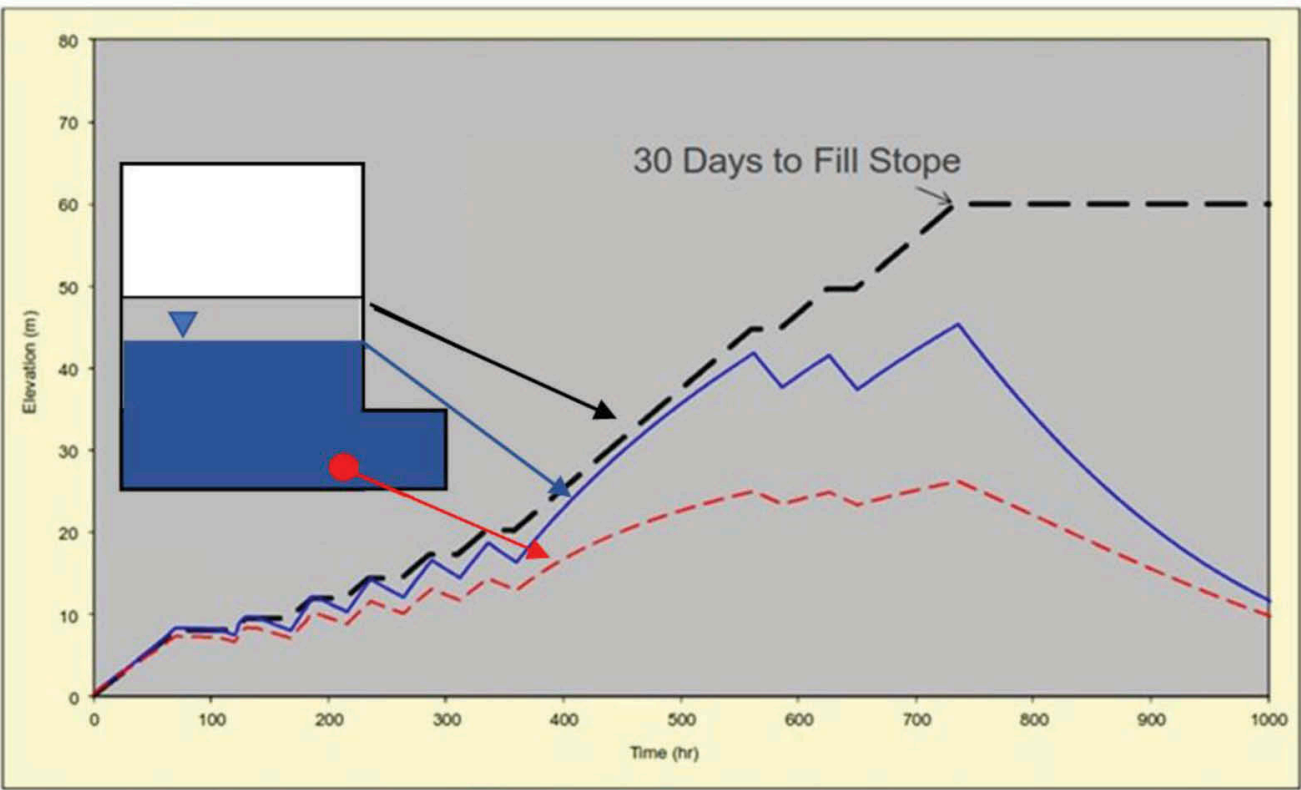

Figure 6. Water balance model for typical Malu stope with $32 \mathrm{~mm} / \mathrm{hr}$ permeability.

While the test results show that a reduction in cyclone feed density (from 38 to 20\%) delivers a significant increase in permeability and underflow solids content, the drawback is a 3 -fold increase in flows. This results in the need for a significant increase in pumping and cyclone cluster capacity. 


\subsection{Binder dosage system}

The other notable compromise of the originally skid mounted CHF plant is the need to pump the cyclone underflow product into the vortex mixer for binder addition. To investigate the potential impact of this design on the overall performance, cylindrical and "Warman" slump testing was undertaken on the cyclone underflow product. Photographs of cylindrical slump testing on the cyclone underflow product are presented in Figure 7.

After addition of binder, the CHF solids content (w/w) would be upto $80 \%$ during operation. Given the results of rheology testing and pump analysis it is expected to be necessary to dilute the CHF product to $75-76 \%$ to facilitate conventional centrifugal pumping. Water balance analysis showed that this additional dilution of cyclone underflow product had the potential to increase the duration required to fill a stope by over $65 \%$.

Given this delay the decision was taken to raise the entire cyclone cluster to allow the cyclone underflow to flow under gravity into a vortex mixer, where it is combined with binder, before flowing under gravity into the borehole. The resulting CHF plant layout is presented in Figure 8. Also presented in Figure 8 is a photograph of the produced high-density $\mathrm{CHF}$ material after settling in a measuring cylinder. This photograph shows the very small amount of bleed water generated after deposition.

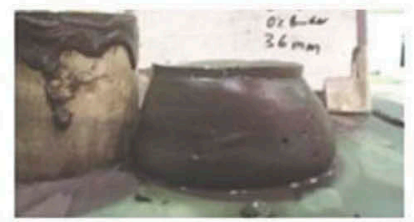

$79 \%$ Solids

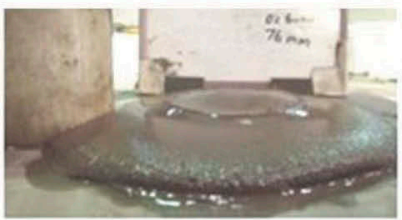

$77 \%$ Solids

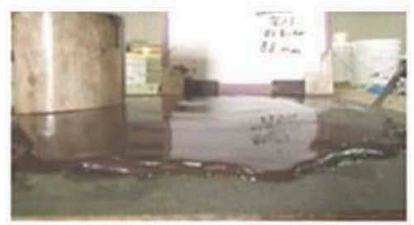

$75 \%$ Solids

Figure 7. Photographs of $\mathrm{CHF}$ at different solids contents.
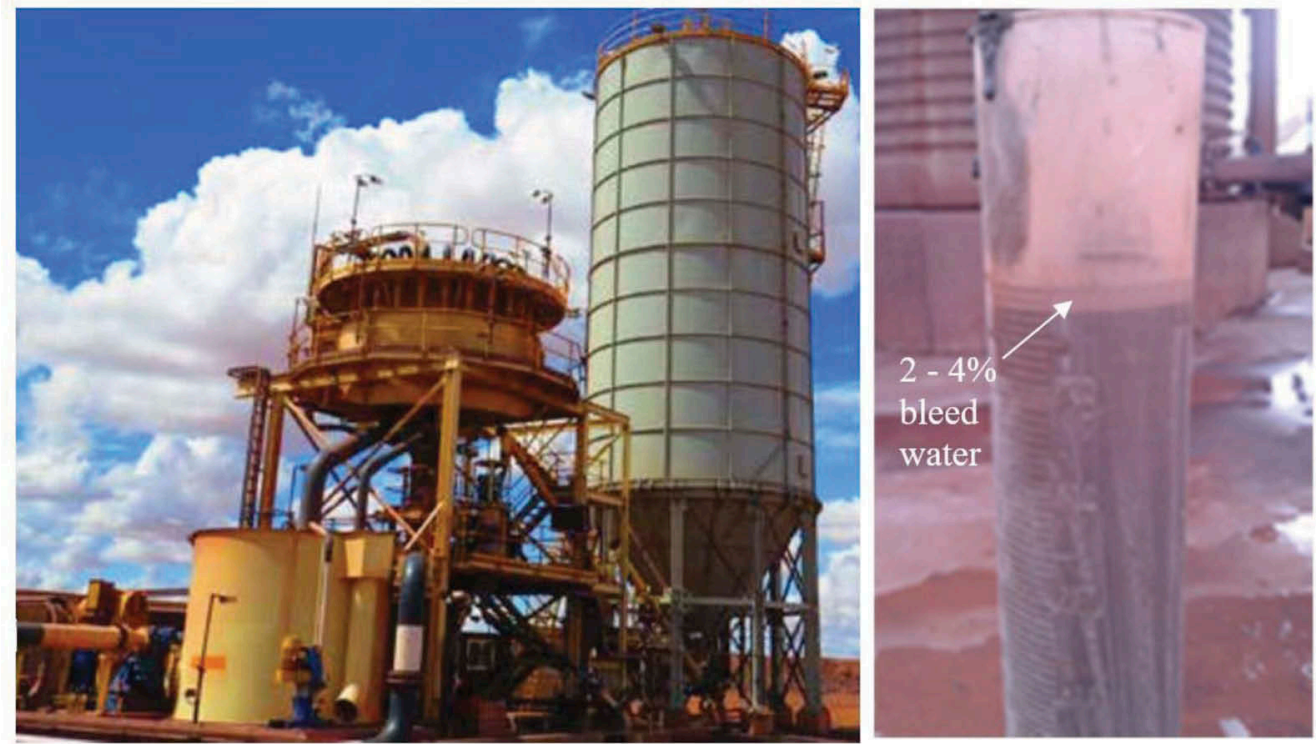

Figure 8. Photograph of Malu CHF plant and Malu CHF material. 


\section{OPERATING EXPERIENCE}

\subsection{Stope drainage}

As detailed by Kuganathan (2002) and Helinski \& Grice (2007), fundamental to safe and efficient hydraulic filling operations is careful stope water balance management. At Prominent Hill the stope water balance is managed through the combination of water balance modelling and in situ pore water pressure monitoring. Water balance modelling combines the actual placed fill characteristics (solids content and flowrate from plant quality control testing), with stope geometry data to represent the stope performance. The model is calibrated against in situ fill height and water pressure measurements in accordance with the method described in Helinski \& Grice (2007).

This approach proved to be largely successful with back calculated permeability and density measurements typically being very similar to values measured in the quality control testing. However, on a number of occasions increased and reduced stope drainage rates were identified through the in situ pore pressure monitoring.

Examples of different stope drainage conditions are presented in Figures 9 and 10, which show in situ piezometer measurements superimposed over water balance model output from stopes that drained and did not drain effectively. Fill with favourable drainage conditions showed a much slower increase in water pressure during filling and a much faster drop in water pressure during drainage periods.

In cases where improved drainage was observed filling rates were increased to accelerate stope turn-around times. Examples of cases where stope drainage was shown to be problematic include:

- A case where rouge groundwater was entering the stope leading to increased stope water addition and consequently higher than expected pressures.

- A case where an error occurred while calculating fill permeabilities. Following higher than expected water pressures, further analysis of quality control testing showed lower than expected fill permeability.

On these occasions filling and drainage periods were adjusted to manage the adverse stope drainage conditions.

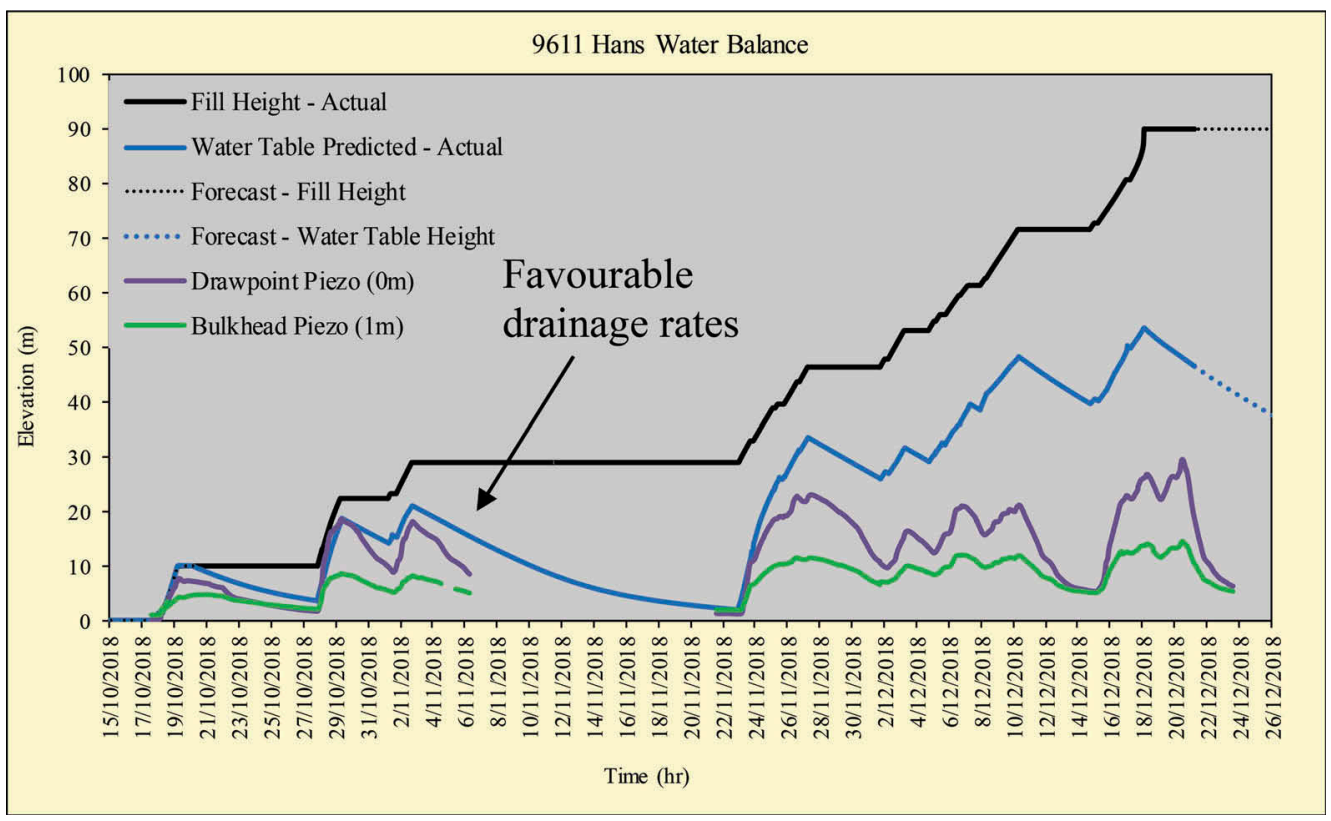

Figure 9. Water balance model with in situ monitoring showing a well-draining stope. 


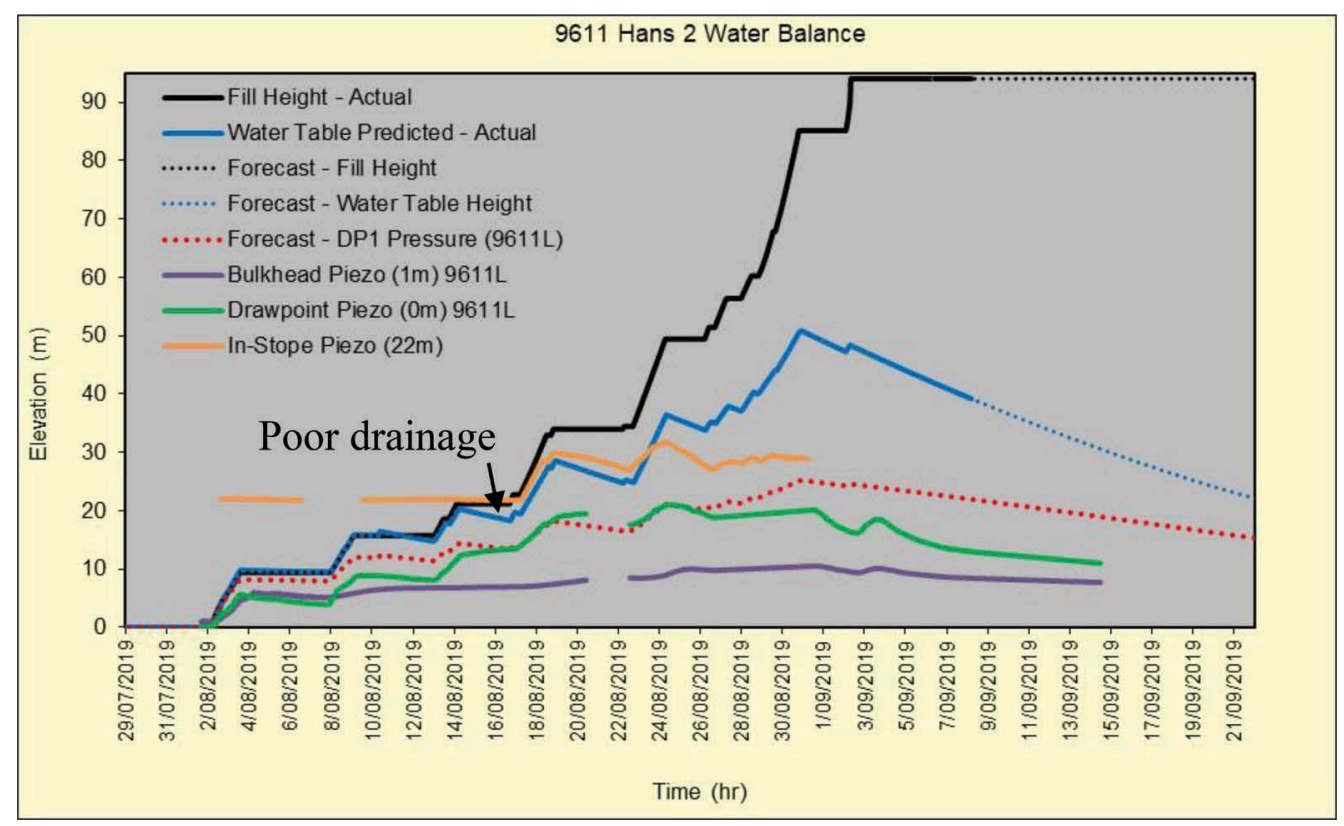

Figure 10. Water balance model with in situ monitoring showing a poorly draining stope.

\subsection{Quality control testing}

The quality control testwork regime included unconfined compressive strength testing after hydration periods of 3, 28 and 240 days hydration. Each of the 3-day tests was multiplied by an amplification factor to extrapolate the value to a longer-term hydration point. Where extrapolated 3-day strengths indicated a trend of lower longer-term strengths, the fill binder content was increased to a level necessary to, not only achieve the target strength, but to a level that adequately compensated for the lower strength layer to ensure exposure stability. Throughout the operation this adjustment was necessary on a number of occasions.

Another interesting learning from quality control testing was in relation to binder types. Low Heat binder is adopted in operation, which is a blend of GP Cement, Granulated blast Furnace Slag (slag) and Kiln dust. The supplier's specification notes a Slag content of $50-70 \%$. During the latter part of 2018 the binder supplier steadily increasing their slag content. To illustrate the significance of this change Figure 11 presents the CHF strengths (for mixes containing 6.0 and $6.5 \%$ binder) against time. Also presented in this plot is the $\mathrm{Al}_{2} \mathrm{O}_{3}$ content of the binder (a product only present in the slag component of the blend) plotted against time.

While its acknowledged that other factors also contribute to the resulting strength, Figure 11 shows a clear trend of increasing strength with increasing $\mathrm{Al}_{2} \mathrm{O}_{3}$ content (representing slag content).

On this basis of these results steps were taken to tighten the range over which binder components were blended.

\subsection{Underground reticulation system pipework}

To maintain the high-density CHF in suspension it is necessary to transport the material at velocities in excess of $2.1 \mathrm{~m} / \mathrm{s}$. At such high velocity pipe wear can be problematic and to manage wear it was deemed necessary to include a protective lining for the underground steel reticulation pipework. For this project $6 \mathrm{~mm}$ thick hot vulcanised rubber lined steel piping was adopted. Flanged couplings were adopted to ensure the rubber lining properly wrapped 


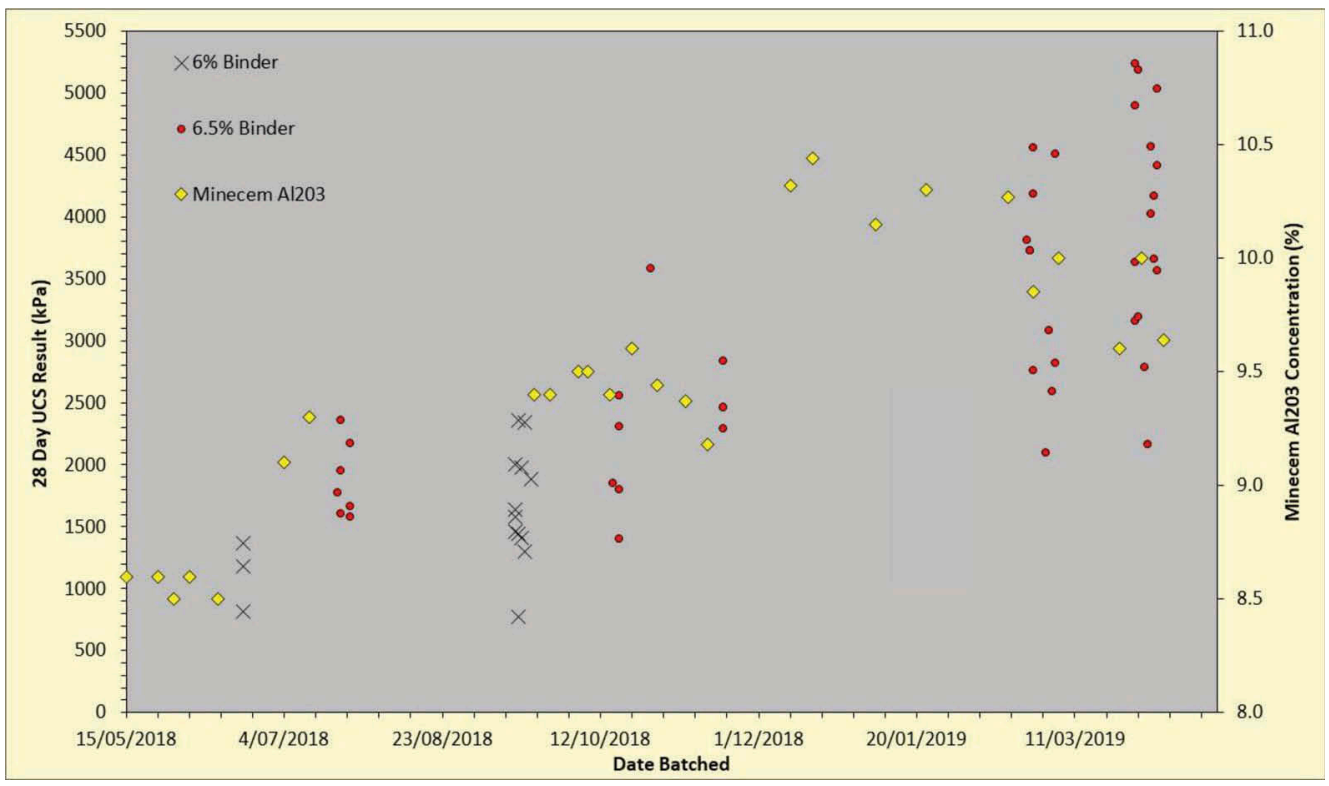

Figure 11. $\mathrm{CHF}$ strength and $\mathrm{Al}_{2} \mathrm{O}_{3}$ content plotted against time.

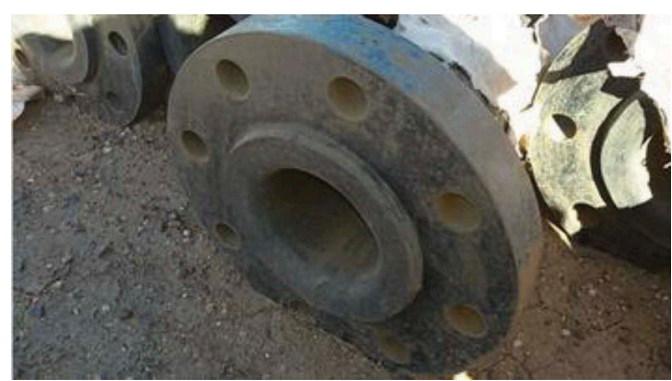

Figure 12. CHF reticulation system pipework.

around the pipe ends and minimise the likelihood of delamination. A photograph showing this pipe is presented in Figure 12.

The experience with this pipeline solution was favourable with limited issues relating to wear or rubber "lifting" during the first 3 years, or approximately $500,000 \mathrm{~m}^{3}$ of operation (design life). After 3 years some wear and rubber lifting issues were encountered. This manifested in rubber flaps lifting and blocking the reticulation system.

Figure 13 presents the cumulative system downtime, attributed to rubber lining issues verses fill quantities placed.

Figure 13 shows that the rubber pipe lining performed well for the first $500,000 \mathrm{~m}^{3}$, but after this the associated downtime increases exponentially. This suggests that, in this case, the design life of the solution is approximately $500,000-750,000 \mathrm{~m}^{3}$.

Due to concerns about damaging the rubber lining during pipe cleaning all cleaning was undertaken using high pressure water sprays (rather than drill strings). This method was largely successful for clearing cured CHF and post cleaning inspections indicated that this method did not appear to damage the lining. 


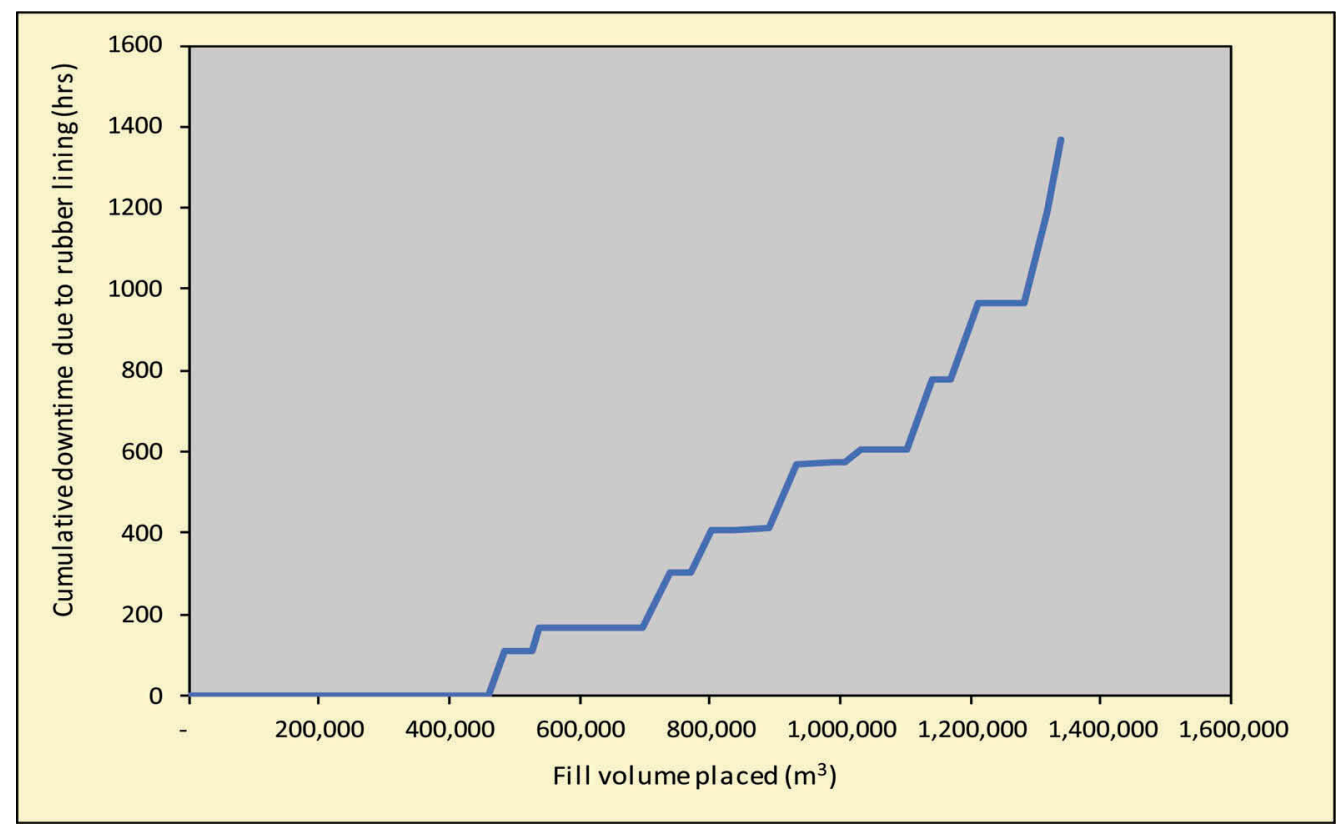

Figure 13. Reticulation rubber lining downtime verses fill placed.

Surface boreholes were lined with 200NB Schedule 40 steel with $10 \mathrm{~mm}$ alumina ceramic sleeve inner lining. Some problems were encountered during installation due to the accumulation of minor casing length discrepancies and the lesson taken from here is to stipulate the ceramic lining length, rather than the total pipe length (i.e. including threading). While we understand that some issues have been encountered with this product at other sites, this casing solution proved largely successful in our application.

Due to the favourable ground conditions, internal boreholes are typically left unlined. Over the life of the operation this has proven to be a good decision with no reported cases of borehole collapse.

\subsection{Internal horizontal borehole}

One particularly unique component of the reticulation system is $110 \mathrm{~m}$ long horizontal boreholes. These are used to avoid reticulation pipework being installed in major travel ways, such as the decline, to prevent any disruptions to ore haulage in the event of reticulation issues.

A schematic showing the geometry of the boreholes is presented in Figure 14. Also presented in Figure 14 is a photograph showing installation of the casing in a horizontal borehole.

Initial attempts to drill long horizontal holes using an in the hole hammer drill rig were not successful, with holes drifting well off target. This issue was then resolved through the introduction of a raisebore drill. The raisebore drill was oriented horizontally, with holes targeting a design incline 1 degree above horizontal, which was primarily to assist with flushing of drill cuttings. In total 2 operational holes were successfully drilled. The holes are cased with an outer $200 \mathrm{NB}$ schedule 80 steel casing with threaded joints between lengths and then an inner casing of $125 \mathrm{NB}$ schedule 120 steel pipe with threaded joint. The horizontal holes are lined to facilitate periodic replacement of the casing. The outer casing provides protection against the $125 \mathrm{NB}$ pipe becoming grouted in should a failure occur. In the event of a blockage, the casing could be easily removed and replaced rather than re-drilling with a raisebore. 

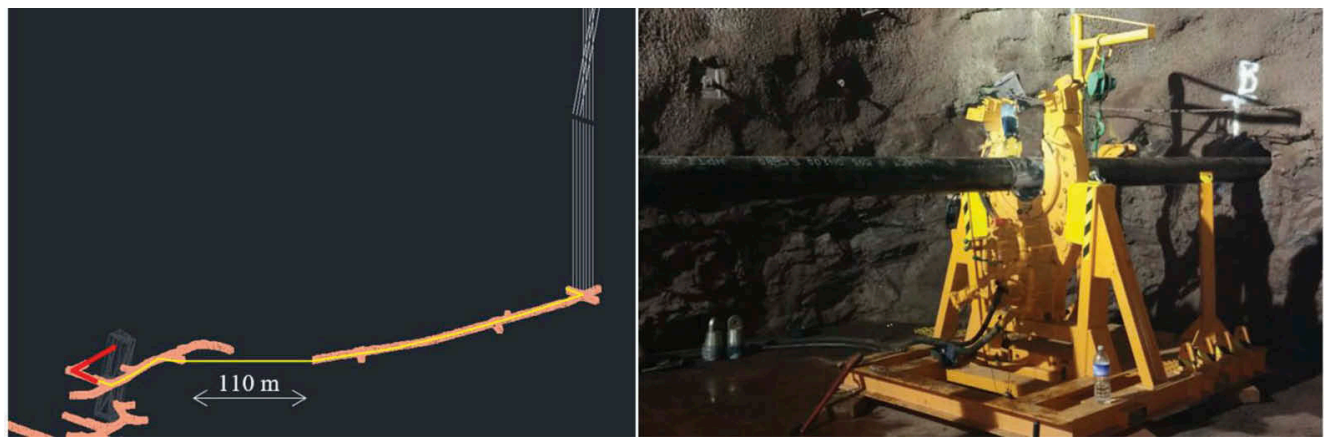

Figure 14. Horizontal internal borehole (a) design and (b) being drilled.

\subsection{Reticulation system blowback}

The surface borehole collar area was designed in a manner that the hydraulic fill is permitted to flow directly into the borehole with a breather hole located at the borehole entry point. After operating for a short period of time (approximately 15 minutes) significant borehole "blowback" occurred, which effectively stopped CHF flowing. The blowback is expected to be a result of air entering the system at the vortex mixer, an expansion of the borehole (from 8 " to 12 " diameter, see Figure 15) midway along the surface borehole leg as well as the low viscosity of the CHF (which prevented release of this pressure).

To resolve the issue, a series of "breather holes" were drilled into the borehole on the intermediate level. These holes act to vent any air pressure accumulation. A photograph showing the mid-height level with breather holes venting water, during a borehole flush, is presented in Figure 15.

This experience demonstrated that, while borehole air entrainment is not typically problematic with (more dilute) hydraulic fills, when producing high-density CHF care should be taken to manage borehole air entrainment using similar design strategies to those commonly adopted on paste fill systems.

\subsection{Horizontal exposures}

The mining sequence at Malu requires fill masses to be exposed over very large horizontal expanses (up to $30 \mathrm{~m} \times 30 \mathrm{~m}$ ) when extracting underlying ore. Our experience has shown that
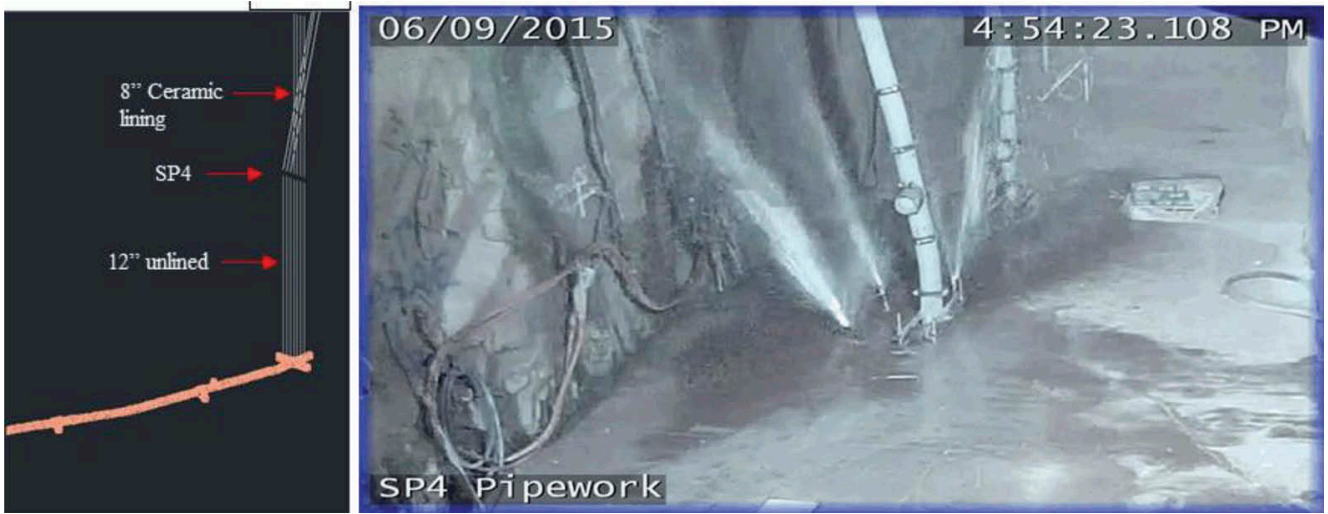

Figure 15. Surface borehole sketch and photograph showing blowback at mid borehole level. 
during deposition the meandering "beaching" process tends to create stratified layers with horizontally oriented cold joints. An example of this is presented in Figure 16, which shows a photograph of an exposed paste fill mass that was placed with a continuous fill run. Due to these "cold joints" it was not considered appropriate to adopt the analytical solutions proposed by Mitchell (1991) (which assume a continuum "massive" fill mass) for the proposed large exposures. Rather, analysis was undertaken using a "dis-continuum" modelling methodology, where horizontally oriented cohesionless interface elements were inserted to represent the cold jointing. This model is presented in Figure 16, which shows the deformed mesh with interface elements represented by pink lines.

With the presence of the cold joints extreemly high strengths are required to totally eliminate dilution, therefore rather than providing a deterministic solution, the results were presented in a series of design charts that relate the expected dilution to prescribed fill layer strength. This design chart is presented in Figure 17.
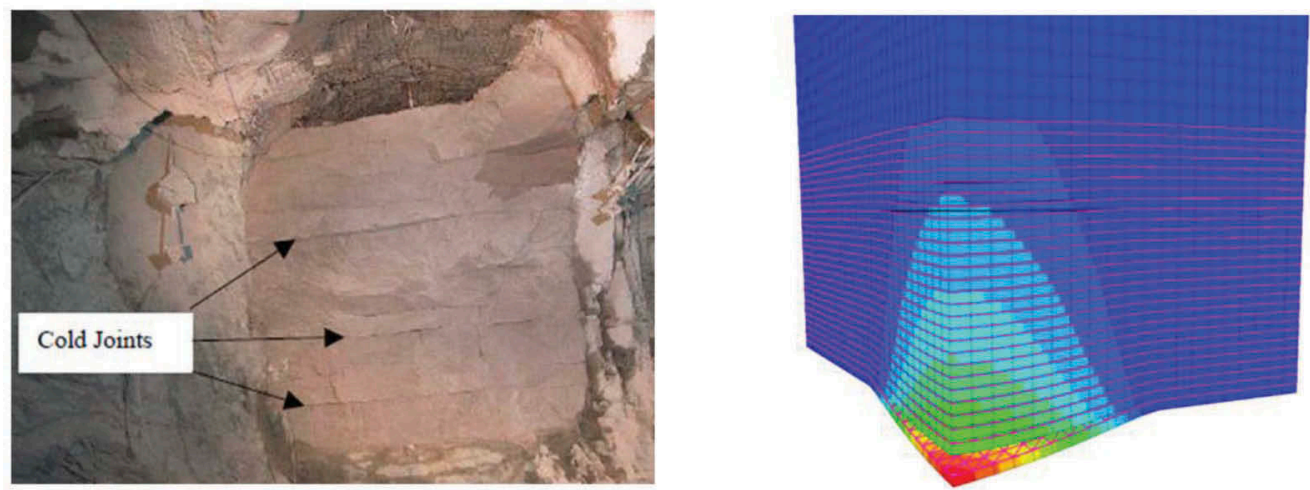

Figure 16. Photograph of cold joints and model used for horizontal exposure analysis.

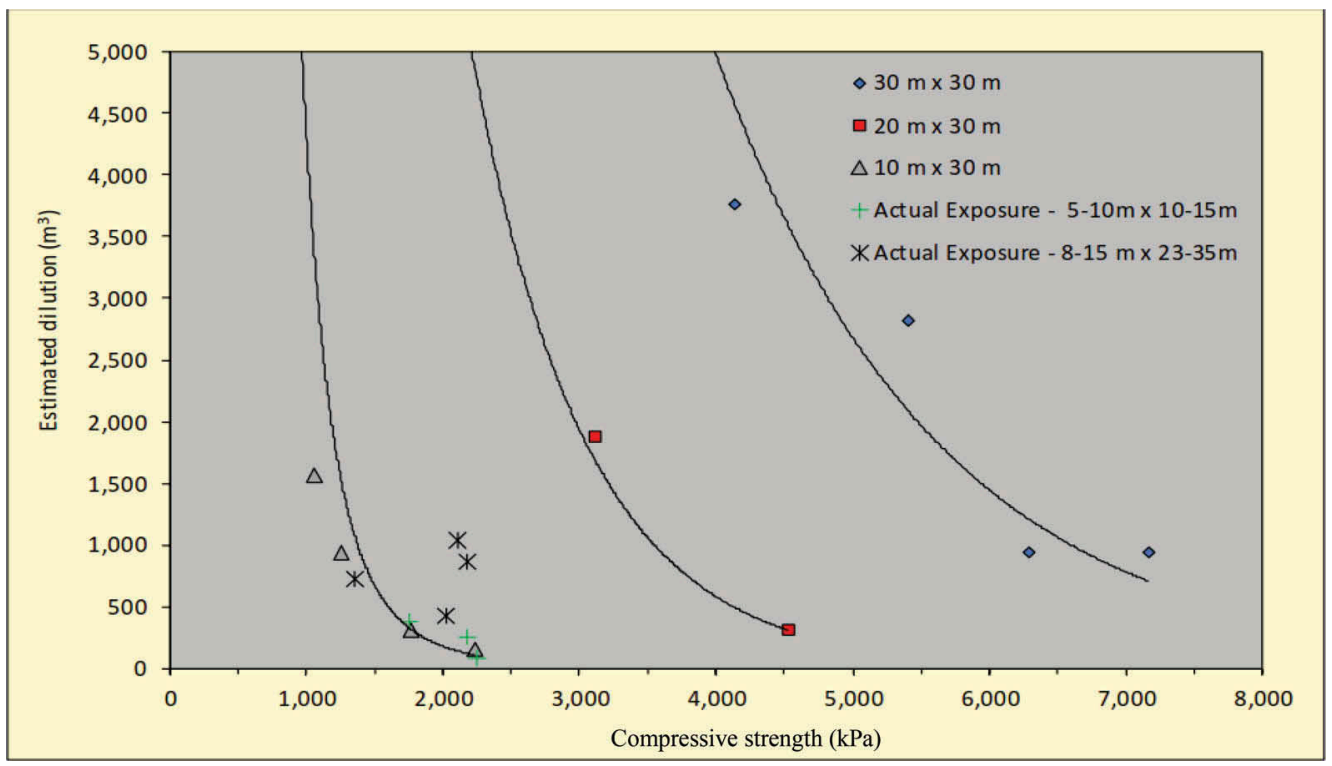

Figure 17. Horizontal exposure design charts with field data. 
Superimposed over Figure 17 are observed dilution levels against actual fill strength (from Malu). The faviourable comparison btween the modelling and acutal dilution levels indicate that the modelling approach provides a reasonble representation of the performance.

\section{CONCLUSION}

This paper presents a case study of the cemented hydraulic fill system at OZ Mineral's Malu underground mine. The major learnings from the design and operational experience include:

- The importance of full-scale cyclone trials during design to:

o ensure that the cyclone underflow geotechnical characteristics can be properly represented.

o ensure that the process design, most notably the desliming circuit, can be properly sized to suit the needs of the mining operation.

- With suitable process design focus high density hydraulic fill systems can be developed. However, subtle design shortcuts can compromise the ability to produce high density hydraulic fill, which have a significant impact on the rate at which underground stopes can be filled.

- Water balance modelling combined with calibration against in situ pore pressure monitoring can provide an effective means of accelerating fill rates where appropriate and managing safety risks under adverse conditions.

- Minor variations in binder constituents can have a significant impact on resulting fill strengths. When establishing fill operations care should be taken to establish tight control over any binder blending.

- Hot vulcanised rubber lining can form an effective pipe wear protection lining system, but in our experience the lifespan of this system was realistically less than $750,000 \mathrm{~m}^{3}$ of fill.

- With high density hydraulic fill systems, specific consideration should be given to minimising air entry into the reticulation system as the lower viscosity of the slurry can prevent air release leading to significant borehole "blow back" events.

- When simulating large horizontal exposures, the presence of horizontally oriented "cold jointing" makes it difficult to totally eliminate dilution. Continuum analysis doesn't provide a reasonable representation of unravelling during horizontal exposures and rather discontinuum modelling appears to provide a rational approach for estimating dilution.

\section{BIBLIOGRAPHY}

Cowling R, Grice A.G. and Isaacs L.T. 1988. Simulation of hydraulic filling of large underground mining excavations. Proc 6th Conf on Numerical Methods in Geomechanics, Innsbrück, Balkema, Rotterdam, pp 1869-1876.

Helinski, M. Grice, A.G. 2007. Water management in hydraulic fill stopes, Minefill '07 Innovations and experience in minefill design, Montreal April 29-May 3. \# 2480.

Kuganathan, K. 2002. 'A method to design efficient mine backfill drainage systems to improve safety and stability of backfill bulkheads and fills', Proceedings of the 8th AusIMM Underground Operators' Conference"growing our underground operations", Australasian Institute of Mining and Metallurgy, Carlton, pp. 181.

Mitchell, R.J. 1991. Sill Mat Evaluation Using Centrifuge Models. Mining Science and Technology, Elsevier Science Publisher B.V., 13: pp. 301-313. 